\title{
Oral health behavior and prevalence of dental caries among 12-year-old school-children in Dar-es-Salaam, Tanzania Mwakatobe AJ ${ }^{1}$, Mumghamba EGS ${ }^{2}$ \\ ${ }^{1}$ School of Assistant Dental Officers (ADO), Muhimbili National Hospital, Dar-es-Salaam, Tanzania. ${ }^{2}$ School of Dentistry, Department of Restorative Dentistry, Muhimbili University College of Health Sciences (MUCHS), Dar-es-Salaam, Tanzania.
}

Mwakatobe AJ, Mumghamba EGS: Oral health behavior and prevalence of dental caries among 12-year-old schoolchildren in Dar-es-Salaam, Tanzania. Tanz Dent J 2007; 14 (1): 1-7

\begin{abstract}
Aim: To study Oral health behavior and prevalence of dental caries, among 12-year-old pupils in Dar-es-Salaam, Tanzania. Materials and methods: This was a cross-sectional study that involved 310 pupils of 12-year-old (males $43.5 \%$ and females $-56.5 \%$ ). Oral health related behavior and knowledge on causes and prevention of dental caries were investigated using a structured questionnaire. Caries experience was assessed using WHO methods. Results: Tooth brushing at least once/day was reported by $92.1 \%$ of the children and $71.9 \%$ used toothpaste. Children reported to consume sugary snacks/drinks more often at home (64.5\%) than in school (35.5\%). Most of the pupils (76.1\%) had never visited a dentist. Most children (71.9\%) indicated sugary snacks as the main cause of dental caries, and for prevention, they recommended avoiding sweets/sugary foods (53.5\%), and tooth brushing (40.3\%). The mean Decay-Missing-Filled-Teeth (DMFT) was $0.76 \pm 1.17$ (SD), was significantly higher among girls $(0.84)$ than boys $(0.64),(\mathrm{P}=0.02)$. A total of $58.4 \%$ of the participants were caries free. Higher caries experience was related to lower brushing frequency, irregular use of toothpaste and high frequency of sugary snack consumption ( $\mathrm{P}$ $<0.05)$. Conclusions: The prevalence of dental caries among 12-year-olds was lower than the WHO global goal, knowledge on the causes and prevention of dental caries were reasonably good, and consumption of sugary food stuffs was done more at home than in schools. Most of the children had never visited a dentist.
\end{abstract}

Key Words: Dental caries, DMFT, tooth brushing, Sugary-food-stuffs, 12-year-old children.

Correspondence: Dr. Ambege Jack Mwakatobe, School of Assistant Dental Officers (ADO), Muhimbili National Hospital, P.O.Box 65102, Dar-es- Salaam, Tanzania. E-mail: ambege@yahoo.com

*Part of this work was presented at the Tanzania Dental Association, $19^{\text {th }}$ Scientific and Annual General Meeting, $22^{\text {nd }}$ $-24^{\text {th }}$ September 2004, Golden Tulip Hotel, Dar-es-Salaam, Tanzania.

\section{Introduction}

Several studies have been conducted on the trend of dental caries prevalence within different populations in different countries. Studies in many developed countries show a decline in dental caries prevalence among their communities $(1,2)$ while the decline in some of these countries, has been questioned $(3,4)$. It is well known that in most developing countries, the provision of preventive health services is still poor $(5$, $6)$. Oral health programs in these countries are adversely affected by poverty and unawareness, while in the meantime socioeconomic factors influence changes in lifestyle. Although caries level reported in Tanzania is still low, some researchers have warned for the possible rise of dental caries prevalence as soon as economic situation allows a changed life style $(7,8)$.

A low caries rate in children has been associated with total intake of sugars of $10 \mathrm{~kg}$ per person per year (about $30 \mathrm{~g} /$ day); caries development increases sharply with intakes of $15 \mathrm{~kg}$ upwards (9). Per capita consumption of sugar in Tanzania is still low; however there has been an increase from 4.4 Kg-Raw value in 1991 to $6.2 \mathrm{Kg}$-Raw value in 2000 (10). Higher caries prevalence is anticipated following increased exposure to Sugary-food-stuffs, while for most people fluoridated toothpaste and comprehensive dental care is not readily available (6). Monitoring of changes in the risk factors such as sugar consumption, and behavior factors such as teeth brushing and use of fluoridated tooth paste are important factors in adjusting the ongoing preventive activities and the management of oral health services in the country (11). In Tanzania, the health authorities have shown growing interest into the establishment of community-based oral preventive programs, however, data on oral health behavior for children and adults are scarce (12). Therefore before planning can be made for any effective intervention, it is important to have information on the knowledge and behavior related to oral health as well as the updated situation on dental caries. The aim of this study was to determine the knowledge and behavior on oral health 
and prevalence of dental caries among the 12-yearold pupils in Dar-es-Salaam, Tanzania.

\section{Materials and Methods}

This study was conducted in Dar-es-salaam in the year 2003. Dar-es-salaam is the largest and economically advanced city with the most factories and industries in the country. The total number of government and private primary schools in Dar-esSalaam in the year 2003 was 286 whereby 119 schools were in Kinondoni municipality, and for Temeke municipality and Ilala municipality there were 76 and 91 schools, respectively. Due to constraints in time and resources, three public primary schools, one from each of the three municipalities were conveniently selected to take part in the study. All three schools were located in the urban parts of their respective municipality. The number of pupils per class in the surveyed schools ranged from 33 to 76 . The three schools had 11 streams of standard (S)-V with a total of 562 pupils. There were nine streams of S-VI in all the three schools with a total of 421 pupils. Therefore the S-V and S-VI in all the three schools had in total 983 pupils. To have the minimal interference in the schools' teaching activities, the study was conducted in two sessions, one in morning and the other on the afternoon where one or two classes were invited at a time for interview and clinical examination. Two classes of S-V and/or S-VI Children from each school were randomly selected and among them, sorted the 12 -years-olds using school registry by the help of class teachers.

\section{Table 1: Distribution of pupils with regard to their knowledge on the causes and prevention of dental caries $(n=310)$}

\begin{tabular}{|c|c|c|}
\hline $\begin{array}{l}\text { quiry on causes and prev } \\
\text { ntal caries }\end{array}$ & & $\begin{array}{l}\text { nse } \\
(\%)\end{array}$ \\
\hline Causes of dental caries (respon & 10) & \\
\hline Sweets/sugary foods & 223 & $(71.9)$ \\
\hline Not cleaning/brushing teeth & 44 & $(14.2)$ \\
\hline Microorganisms/worms & 24 & $(7.7)$ \\
\hline Don't know & 19 & $(6.1)$ \\
\hline Prevention of teeth decay ( $\mathrm{r}$ & $=310)$ & \\
\hline Avoid sweets/sugary foods & 166 & $(53.5)$ \\
\hline Teeth & 125 & $(40.3)$ \\
\hline Other methods & 19 & $(6.1)$ \\
\hline
\end{tabular}

A total of 310 schoolchildren participated in the study. The study population was not balanced by gender; there were 175 (56.5\%) girls and 135 (43.5\%) boys. Information regarding children's oral health knowledge, oral hygiene behavior, sugar consumption habits and frequency of consumption of sugary snacks was collected through interview using a questionnaire that had most of the structured questions (Yes or No, and those that included selection from the specified alternatives) and very few open-ended questions. The questionnaire was initially developed in English and later translated into Kiswahili, the national language. The translated Kiswahili version was back translated, and then both the original and back translated versions were compared, reviewed and pre-tested. One principal investigator and 2 trained researcher assistants collected the data. The interviewers filled in the blanks or "marked" the appropriate answer in the questionnaire forms after clearly reading the question to the interviewee. After the interview session, clinical examination of all subjects was done by one calibrated examiner under natural light, scoring the decayed, missing and filled-teeth (DMFT) according to WHO criteria (13). Disposable instruments were used for examination (plane oral mirrors, CPI probes, tweezers and instrument trays). Ethical clearance to conduct the study was granted by the Ministry of Health. Permission to carry out the survey in schools was sought from the Ministry of Education and Culture, Municipal Councils and School HeadTeachers. Verbal informed consent to participate in the study was obtained from the pupils.

Data were first entered into Excel data sheet and then analyzed by using Epi Info 2002 Revision 2. Frequency tables were generated accordingly and the descriptive statistics are presented by using mean and standard deviation. The differences in the occurrence of the studied conditions at different groups were tested using Chi-square and Student's t-test accordingly whereby the level of significance was set at $\mathrm{P}<0.05$.

\section{Results}

The findings on the pupil's knowledge on the causes and prevention of dental caries are presented in Table 1. It was revealed that most pupils believe sweet foods to be the main cause of dental caries. In response to an open-ended question asking, "What do you think is the cause of tooth decay?" Sweet foods were mentioned by $71.9 \%$ of the study participants, poor oral hygiene/not brushing (14.2\%), microorganisms (7.7\%) and don't know (6.1\%). With regard to dental caries prevention, as most pupils believe sugary foods to be the main culprit, high percentage of pupils recommended avoiding sweets or sugary foods $(53.5 \%)$, tooth brushing $(40.3 \%)$, and other measures such as regular dental visits, use of medicines and avoiding very cold drinking water (6.1\%). Slightly more than half of the pupils $(59.4 \%)$ reported to brush their teeth twice daily or more. 
However, there were no substantial differences in these oral health care habits in relation to gender.

Distribution of pupils according to their reported visits to dentists and persons who taught them how to brush is shown in Table 2. A large number of pupils $(76.1 \%)$ had never been to a dentist for treatment or for dental check-up. Most of the children were taught how to brush teeth either by their mothers $(51.3 \%)$ or by themselves (32.6\%). Only 2 children $(0.6 \%)$ claimed to have received teeth brushing instruction from a dentist or any other medical personnel.

Table 2: Distribution of pupils according to their reported visits to dentists and persons taught them how to brush $(n=310)$

\begin{tabular}{lcc}
\hline \multicolumn{3}{l}{ Inquiry on visits to a dentist and Response } \\
tooth brushing instructor & $\mathrm{n}$ & $(\%)$ \\
\hline Have you ever been to a dentist? & & \\
Yes & 74 & $(23.9)$ \\
No & 236 & $(76.1)$ \\
Who taught you on how to do tooth brushing \\
Myself & 101 & $(32.6)$ \\
Mother & 159 & $(51.3)$ \\
Father & 23 & $(7.4)$ \\
Teacher & 15 & $(4.8)$ \\
Dentist/Nurse & 2 & $(0.6)$ \\
Relatives/Other & 10 & $(3.2)$ \\
\hline
\end{tabular}

The distribution of decayed, missing and filled teeth (DMFT) is shown in Table 3. About 58\% of the pupils were caries-free. The proportion of study participants in relation to decayed teeth (DT) component was higher in girls $(45.7 \%)$ than in boys (31.6\%). The proportion of study participants that had filled teeth (FT) was very low $(0.6 \%)$. A significant proportion of pupils (71.9\%) reported to use toothpaste always during tooth cleaning. Though the self reported frequency of consumption of sugary foods twice a day or more was low (Table 4), children consuming sugary snacks more frequently were found to have more caries than the rest $(\mathrm{P}<0.05)$. According to the results of Chi-square analysis, higher caries experience was related to lower brushing frequency, irregular use of toothpaste and increased consumption of sugary snacks $(\mathrm{P}<0.05)$ (Table 4). The mean DMFT according to gender and school is summarized in Table 5 . The mean caries experience (DMFT) was $0.76 \pm 1.2$ (SD). The caries prevalence using the DMFT index was significantly higher in girls $(\mathrm{DMFT}=0.84)$ than boys $(\mathrm{DMFT}=$ $0.64), P=0.02$. There was no significant difference in the mean DMFT scores among pupils in the three schools studied $(\mathrm{P}>0.05)$.

\section{Discussion}

Because three primary schools involved in the study were located in urban areas, most of the participants were living in urban and peri-urban parts of the city. Children living in rural areas were not represented. However, schools surveyed are public owned and are located in the most densely populated areas of their respective municipalities. According to the Census data in the year 2002, the urban population of the 12 year olds in Dar-es-Salaam (school and non-school going) was 55,734 and with the previously recorded growth rate of about $4.3 \%$ it is estimated that in the time of study there were about 58,130 children (14). It is therefore assumed that, the proportion of subjects examined $(0.5 \%)$, though it was conveniently sampled out to represent the three different districts, still some lessons in relation to urban schoolchildren can be learnt from the present study. Regarding socioeconomic factors, detailed information could not be obtained, as the questionnaire targeted pupils only, who proved to have limited knowledge on their parents/guardians' occupation and education level. However, other distinct dental health factors that can recount on social inequalities in dental caries reduction such as; use of toothpaste, frequency of tooth brushing, sugar consumption and utilization of dental care services were explored.

Though many pupils reported to brush their teeth at least once daily or more $(92.1 \%)$, and use of toothpaste was common (71.9\%), their oral hygiene status can not be claimed to be good as it was not assessed clinically. Furthermore, the technical know how of the teeth brushing procedure might be questioned. Oral hygiene status of previous studied children in Tanzania was found to be poor despite of the claim by many children to brush their teeth every morning (7). Validity of behavioral data has been questioned when data are obtained by inquiries or interviews (15). In this study, some pupils might have misreported their oral health habits. With regard to the frequency of tooth brushing and use of toothpaste over-reporting can be assumed, where as the consumption of sugary snacks and sugary drinks might have been under-reported due to the possibility of reporting the practice that is mostly expected of an individual participant in line with the commonly desired practice.

In response to the question "Who taught you how to brush your teeth?" a significant number of pupils claimed to have been taught how to practice tooth brushing by their mothers. Even if the technical know how, condition of toothbrush, frequency and duration of the procedure might be questioned, this explains the important role of parents particularly mothers in establishing early basic oral health practices to 
children. Continuity and perfection of tooth brushing practice among children is believed to take place in schools where teachers are seen as the main instructors. Good instructions for example by teachers yield good results but not so long standing and therefore the role of parents need to be emphasized (16). In the present study about one third of the children just learnt by themselves on how to brush. May be also they had seen the tooth brushing practice from their fellow children. In addition, due to time that had elapsed between initial teaching on tooth brushing and the reporting in the current study might have affected the responses. However based on the family life in a Tanzanian setting, mothers are the ones that mostly stay with the children than other groups of people such as teachers, dentist/nurse that were mentioned in relation to this inquiry.

Table 3: Distribution of the Decay-Missing-Filled teeth components and caries-free individuals among the 12-year old pupils by gender and place of school

\begin{tabular}{|c|c|c|c|c|c|c|c|c|c|}
\hline \multirow[b]{2}{*}{ Factors } & \multirow{2}{*}{$\begin{array}{l}\text { No. of study } \\
\text { participants }\end{array}$} & \multicolumn{2}{|c|}{ Caries-free } & \multicolumn{2}{|c|}{$\begin{array}{l}\text { Decayed } \\
\text { Teeth }\end{array}$} & \multicolumn{2}{|c|}{$\begin{array}{l}\text { Missing } \\
\text { Teeth }\end{array}$} & \multicolumn{2}{|c|}{ Filled Teeth } \\
\hline & & $\mathrm{n}$ & $\%$ & $\mathrm{n}$ & $\%$ & $\mathrm{n}$ & $\%$ & $\mathrm{n}$ & $\%$ \\
\hline \multicolumn{10}{|l|}{ Gender } \\
\hline Girls & 175 & 91 & 52.0 & 80 & 45.7 & 15 & 8.6 & 1 & 0.6 \\
\hline Boys & 135 & 90 & 66.7 & 43 & 31.6 & 10 & 7.4 & 1 & 0.7 \\
\hline \multicolumn{10}{|l|}{ School } \\
\hline Mapambano & 110 & 67 & 60.9 & 42 & 38.2 & 5 & 4.6 & 2 & 1.8 \\
\hline Uhuru & 102 & 59 & 57.8 & 41 & 40.2 & 10 & 9.8 & 0 & 0.0 \\
\hline Wailes & 98 & 55 & 56.1 & 40 & 40.8 & 10 & 10.2 & 0 & 0.0 \\
\hline All & 310 & 181 & 58.4 & 123 & 39.7 & 25 & 8.1 & 2 & 0.6 \\
\hline
\end{tabular}

Results from the present study shows that children consuming sugary snacks more frequently had more caries than the rest, and this is in agreement with Mazengo and Coworkers report (17). In addition, most pupils did consume sugary snacks/drinks more frequently at home than during school hours. Though the difference between "at home versus at school" sugary snacks/drinks consumption was not statistically significant, clinically it might have some significance in that at home there is a possibility of doing tooth brushing with fluoridated toothpaste for prevention. This again highlights the significant contribution that parents can confer in regulating between meal eating habits of their children in an effort to control dental caries, and underscores the importance of promoting oral health education among adults and at family level (9). These findings are contrary to the anticipation as it had been reported that most pupils consume sugary snacks more frequent during their school hours than at home (18). However, the findings on tooth brushing habit, the common use of toothpaste and the proportion of children consuming sugary snacks are in agreement to what has been reported earlier among urban school children in Tanzania (7).

The proportion of pupils who had never been to a dentist for dental check up or treatment was high and it is in agreement with the findings by Varenne and Coworkers, but the level of self-reported oral home care and use of fluoridated tooth paste during tooth brushing is much higher than that reported in Burkina Faso (19). Our findings supports other studies suggesting that, many families in the developing world don't have a custom of visiting a dental clinic and that seeking professional oral health care, if available and accessible, is mainly influenced by pain (12). Comprehensive dental care in Tanzania is not in place due to financial constraints and other reasons (6). According to the 2001 annual return for oral health care, out of 18,288 caries cases in Dar-essalaam region only 3,244 conservations were done (20). In our study, the filled teeth (FT) component in the overall DMFT was very low. However, this presents a treatment initiative better than in Nigeria where no fillings were encountered among the 12 year olds (21). The possible explanation for such an outcome is that most children seek oral health care late when the dental caries had already advanced and that the only readily available treatment is tooth extraction (6).

Economic and social changes affect life-styles and patterns of sugary food consumption of today's Tanzanian child population. In contrast to the countries of developed market economy where the provision of preventive dental health services is well established, many children in Tanzania don't access preventive dental services, dental awareness is still low and fluoridated toothpaste is not accessible to every child $(6,16)$. Therefore, dental caries 
prevalence is anticipated to increase following increased exposure to the determinants of dental caries (6), and even by not controlling the already existing low exposure with increasing time (18).

The WHO global goal for 12-year-olds is DMFT = 3 (21). Tanzanian children of 12-year-old have a slightly higher DMFT than Nigerians $(\mathrm{DMFT}=0.51)$, but lower than the Libyan children (mean DMFT 1.63) $(21,23)$. The caries status of 12-year-olds in the current study $(\mathrm{DMFT}=0.76)$ does not differ much from previous studies of Tanzanian children of relatively the same age $(24,25)$, which is still below the $(\mathrm{DMFT}=1.74)$ reported in the year 2003 from the global caries data bank for the 12-year-old age group (26). Despite the fact that the DMFT score found in this study is slightly higher than results of the same age group found in other studies conducted in the country $(12,27)$ in comparing these findings, the differences in the methodology used, study areas and scoring criteria for dental caries by various examiners should be considered to be among the possible reasons for the observed variation.

Table 4: Caries experience (DMFT) as related to gender, sugar consumption, and oral hygiene practices

\begin{tabular}{|c|c|c|c|c|}
\hline \multirow[b]{4}{*}{ Factors } & \multicolumn{3}{|c|}{ Caries experience (DMFT) } & \multirow[b]{4}{*}{ P-value } \\
\hline & Yes & No & Total & \\
\hline & $\mathrm{n} \quad(\%)$ & $\mathrm{n} \quad(\%)$ & $\mathrm{n} \quad(\%)$ & \\
\hline & $129(41.6)$ & $181(58.4)$ & $310(100)$ & \\
\hline \multicolumn{5}{|l|}{ Gender } \\
\hline Girls & $84(48.0)$ & $91(52.0)$ & $175(56.5)$ & \multirow[b]{2}{*}{0.0093} \\
\hline Boys & $45(33.3)$ & $90(66.7)$ & $135(43.5)$ & \\
\hline \multicolumn{5}{|l|}{ School } \\
\hline Uhuru & $43(42.2)$ & $59(57.8)$ & $102(32.9)$ & \\
\hline Mapambano & $43(39.1)$ & $67(60.9)$ & $110(35.5)$ & \multirow[b]{2}{*}{0.776} \\
\hline Wailes & 43 (43.9) & $55(56.1)$ & $98(31.6)$ & \\
\hline \multicolumn{5}{|c|}{ Place of sugary snacks consumption } \\
\hline School & $50(45.5)$ & $60(54.5)$ & $110(35.5)$ & \multirow[b]{2}{*}{0.3088} \\
\hline Home & $79(39.5)$ & $121(60.5)$ & $200(64.5)$ & \\
\hline \multicolumn{5}{|c|}{ Frequency of Tooth brushing } \\
\hline Not daily & $17(73.9)$ & $6(26.1)$ & $23(7.4)$ & \multirow[b]{4}{*}{0.0004} \\
\hline Once daily & $51(49.5)$ & $52(50.5)$ & $103(33.2)$ & \\
\hline Twice daily & $43(32.6)$ & $89(67.4)$ & $132(42.6)$ & \\
\hline More than twice daily & $18(34.6)$ & $34(65.4)$ & $52(16.8)$ & \\
\hline \multicolumn{5}{|l|}{ Toothbrush Duration } \\
\hline More than 3 months & $64(53.8)$ & $57(46.2)$ & $121(13.0)$ & \multirow[b]{2}{*}{0.0012} \\
\hline Less than 3 months & $65(35.3)$ & $124(64.7)$ & $189(30.5)$ & \\
\hline \multicolumn{5}{|l|}{ Use of Toothpaste } \\
\hline Not always & $53(60.9)$ & $34(39.1)$ & $87(28.1)$ & \multirow[b]{2}{*}{0.0000} \\
\hline Always & $76(34.1)$ & $147(65.9)$ & $223(71.9)$ & \\
\hline \multicolumn{5}{|c|}{ Frequency of sugar consumption } \\
\hline Thrice a day & $34(52.3)$ & $31(47.7)$ & $65(21.0)$ & \multirow[b]{3}{*}{0.0045} \\
\hline Twice a day & $59(47.2)$ & $66(52.8)$ & $125(40.3)$ & \\
\hline Once a day or less & $36(30.0)$ & $84(70.0)$ & $120(38.7)$ & \\
\hline
\end{tabular}


The proportion of 12-years Tanzanian children that were caries free $(58.4 \%)$ was lower compared to the Nigerian (65\%) and the Indian (77.7\%) children (21, 28 ). Findings in the current study also show that the proportion of caries-free children $(58.4 \%)$ does not seem to significantly improve. Mosha and Scheutz reported the proportion of caries-free Tanzanian children at age 11-years to be $54.4 \%, 54.7 \%$ and $83.3 \%$ for the years 1979,1983 and 1989 respectively (27). This suggests that, despite of the introduction of school-based oral health education in 1982 (7) the incident rate of caries among schoolchildren does not seem to significantly decrease with time. A study in Tanzania by Van Palenstein and Coworkers (16) reported that the implemented school-based Oral Health Education (OHE) program in primary schools did not result in significant reductions of caries.

\section{Table 5: Mean DMFT scores of the 12-year old pupils according to gender and school}

\begin{tabular}{lcccc}
\hline Factors & No. of study participants DMFT & SD P-Value \\
\hline Gender & & & & \\
Girls & 175 & 0.84 & 1.18 & \\
Boys & 135 & 0.64 & 1.15 & 0.02 \\
School & & & & \\
$\quad$ Mapambano & 110 & 0.65 & 1.08 & \\
Uhuru & 102 & 0.84 & 1.27 & \\
Wailes & 98 & 0.78 & 1.16 & 0.63 \\
All & 310 & 0.76 & 1.17 & \\
\hline
\end{tabular}

Despite the low caries level reported in Tanzania, many studies have warned of the possible rise of dental caries prevalence as far as economic situation allows a changed life style favoring consumption of sugary food stuffs $(7,8)$ Furthermore, the provision of preventive oral health services in the country is still poor. In other countries where oral health preventive services have been improved, a significant decrease in dental caries has been observed $(29,30)$.

Among factors that were considered as the limitation of the present study was one, "the convenient sampling", a fact which does not allow direct inference and generalization to the total unstudied population. Two, the ability of the pupils to recall for example in the question, "who taught you how to do tooth brushing", since under normal circumstances it is not a serious or crucial issue, there is always high chance of not remembering exactly the "instructor" and in particular when some years have elapsed.

\section{Conclusion and recommendations}

The prevalence of dental caries among 12-year-olds is still low and well below the WHO global goal for 12year-olds, and the self-reported oral health behavioral habits and knowledge level on the causes and prevention of dental caries were found to be reasonably good. However, consumption of sugary foodstuffs was high particularly at home than in schools, consumption of sugary snacks at school was substantial, and that the habit of visiting a dentist for dental check-ups was very low. It is recommended to improvise for oral health promotion programs, regular dental visits for dental check-ups, control consumption of sugary snacks, and supply of affordable bio-available fluoridated toothpastes.

\section{Acknowledgements}

We wish to express our gratitude to the school children and teachers of Mapambano, Uhuru Mchanganyiko and Wailes Primary Schools for their kind cooperation and participation in this study. We owe special debt of gratitude to Japan International Cooperation Agency (JICA), Japan International Cooperation Center (JICE), National Institute of Public Health (NIPH) Japan, and to the Ministry of Health and Social Welfare, Tanzania for supporting this study.

\section{References}

1. Murray JJ. Comments on results reported at the second international conference "Changes in caries prevalence". Int. Dent. J. 1994; 44: 457-8.

2. Elmar Reich. Trends in caries and periodontal health epidemiology in Europe. Int. Dent. J. 2001; 51: 392-8.

3. Downer MC. Caries prevalence in the United Kingdom. Int. Dent. J. 1994; 44: 365-70.

4. Bjarnason S. High caries levels: problems still to be tackled. Acta Odont. Scand. 1998; 56: 176-8.

5. Kulak-Ozkan Y, Ozkan Y, Kazazoglu E, Arikan A. Dental caries prevalence, tooth brushing and periodontal status in 150 young people in Instanbul: A pilot study. Int. Dent. J. 2001; 51: 451- 6.

6. Policy guidelines for oral health care in Tanzania. Ministry of Health. 2002; 2-17.

7. Nyandindi U, Palin-Palokas T, Milen A, Robison $\mathrm{V}$, Kombe N. Oral health knowledge, attitudes, behaviour and skills of children entering school in urban and rural areas in Tanzania. Public health 1994; 108: 35-41.

8. Miura H, Araki Y, Haraguchi K, Arai Y, Umenai T. Socioeconomic factors and dental caries in developing countries: a cross-national study. Soc. Sci. Med. 1997; 44: 269-72.

9. World Health Organization. Diet, nutrition and the prevention of chronic diseases. WHO Technical Report Series No. 797, 1990.

10. Mount G, Hume R. Dental caries. UCLA School of Dentistry. 2004; 1-12. http://www.dent.ucla.edu/ce/caries/index.html (accessed on 4/30/2007) 
11. Konig KG. Implications of changes in the caries prevalence on research. Int. Dent. J. 1994; 44: 451-6.

12. Petersen PE, Nyandindi E, Kikwilu E, Poulsen VJ. Oral health status and oral health behavior of school children, teachers and adults in Tanzania. WHO Technical Report. 2002.

13. World Health Organization. Oral health surveys: Basic methods. $4^{\text {th }}$ edition. 1997; Geneva: World Health Organization.

14. Census data for the 12-year olds children in Dares-Salaam, Tanzania (http://www.tanzania.go.tz/census/dsm.htm (accessed on 4/30/2007).

15. Salas-Wadge MH. Use of linear multiple regression analysis on dental survey data. Community Dent. Health 1994; 11: 197-201.

16. Van Palestein Helderman WH, Munck 1, Mushendwa S, Van't Hof MA, Mrema FG. Effect evaluation of an oral health education programme in primary schools in Tanzania. Community Dent. Oral Epidemiol. 1997; 25: 296-300.

17. Mazengo MC, Tenovuo J, Hausen H. Dental caries in relation to diet, saliva and cariogenic microorganisms in Tanzanians of selected age groups. Community Dent Oral Epidemiol. 1996; 24: 169-74

18. Ojofeitimi EO, Hollist NO, Banjo T, Adu TA. Effect of cariogenic food exposure on prevalence of dental caries among fee and non-fee paying Nigerian schoolchildren. Community Dent. Oral Epidemiol. 1984; 12: 274-7.

19. Varenne B, Petersen PE, Ouattara S. Oral health behaviour of children and adults in urban and rural areas of Burk Ojofeitimi EO ina Faso, Africa. Int. Dent. J. 2006; 56: 61-70.

20. Annual return for oral health care 2001, Central Oral Health Unit (COHU), Ministry of Health, Republic of Tanzania, Dar-es-Salaam, 2001.

21. Okeigbemen SA. The prevalence of dental caries among 12 to 15-year-old school children in Nigeria: report of a local survey and campaign. Oral Health Prev. Dent. 2004; 2: 27-31.
22. Nithila A, Bourgeois D, Barmes DE, Murtomaa H. WHO global oral data bank, 1986-96: an overview of oral health surveys at 12 years of age. Bulletin of the World Health Organization.1998; 76: 237-44.

23. Al-Sharbati MM, Meidan TM, Sudani O. Oral health practices and dental caries among Libyan pupils, Benghazi (1993-94 East Mediterr. Health J. 2000; 6: 997-1004.

24. Frencken J, Manji F, Mosha H. Dental caries prevalence amongst 12-year-old urban children in East Africa. Community Dent. Oral Epidemiol. 1986 Apr; 14: 94-8.

25. Mosha HJ, Manji F, Frencken JE, Thaker LS. Changes in dental caries experience of 12-year olds in low fluoride urban and rural areas of Tanzania. East Afr. Med. J. 1991; 12: 963-8.

26. WHO Oral health country/ area profile programme. Cluster of noncommunicable diseases and mental health. Department of management of noncommunicable diseases. Oral Health WHO Collaborating center. Malmo University, Sweden. Global Caries Data for 12year-old age group. 2003. http://www.whocollab.od.mah.se/expl/globalcar. html (accessed on 4/30/2007)

27. Mosha HJ, Scheutz F. Dental caries in the permanent dentition of schoolchildren in Dar-essalaam in 1979, 1983, and 1989. Community Dent. Oral Epidmiol. 1992; 20: 381-2.

28. Saravanan S, Anuradha KP, Bhaskar DJ. Prevalence of dental caries and treatment needs among school going children of Pondicherry, India. J. Indian Soc. Pedod. Prev. Dent. 2003; 21(1): 1-12.

29. Renson CE. Global changes in caries prevalence and dental manpower requirements: 2. The reasons underlying the changes in prevalence. Dent. Update 1989; 16: 345-51.

30. Van Nieuwenhuysen JP, Carvalho JC, D'Hoore W. Caries reduction in Belgian 12-year-old children related to socioeconomic status. Acta Odontol. Scand. 2002; 60: 123-8. 